\title{
Is there a place for bronchiolitis in the COVID-19 era? Lack of hospitalizations due to common respiratory viruses during the 2020 winter
}

Fernando Ferrero ${ }^{1}$ and Maria Ossorio ${ }^{1}$

${ }^{1}$ Hospital General de Niños Pedro de Elizalde

February 26, 2021

\begin{abstract}
It was recently reported that due to the COVID-19 pandemic, in the European winter 2020-2021, bronchiolitis had practically disappeared. But early reports from the southern hemisphere (Australia) raised concerns about a late spring / summer peak. After a full winter season and now ending the summer, we report that there was no peak of common respiratory viruses in late spring / summer in South America.
\end{abstract}

\section{Hosted file}

NoBql_Total.pdf available at https://authorea.com/users/332096/articles/511045-is-therea-place-for-bronchiolitis-in-the-covid-19-era-lack-of-hospitalizations-due-to-commonrespiratory-viruses-during-the-2020-winter

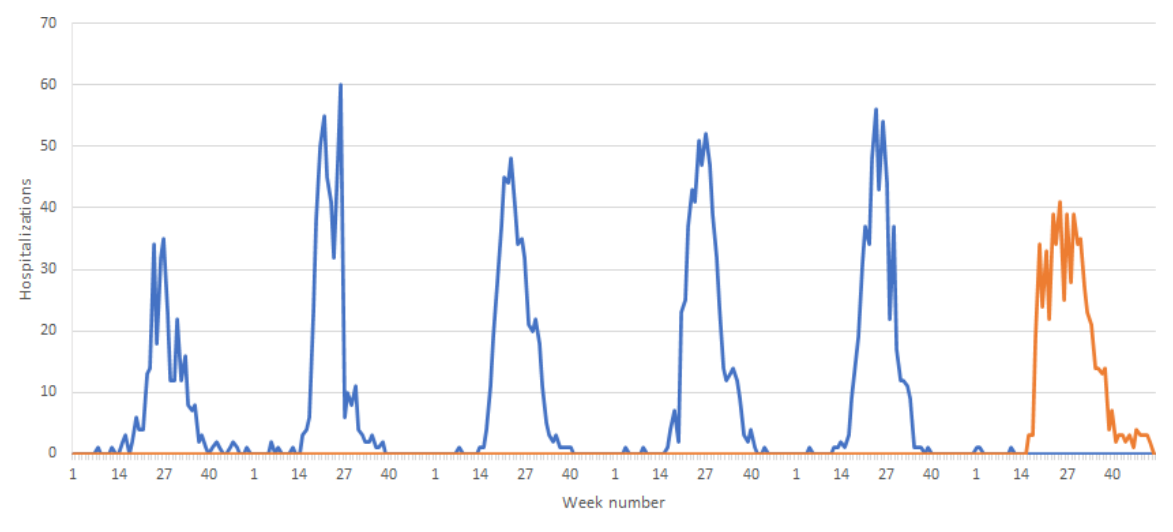

-Common respiratory viruses - SARS-COV-2 


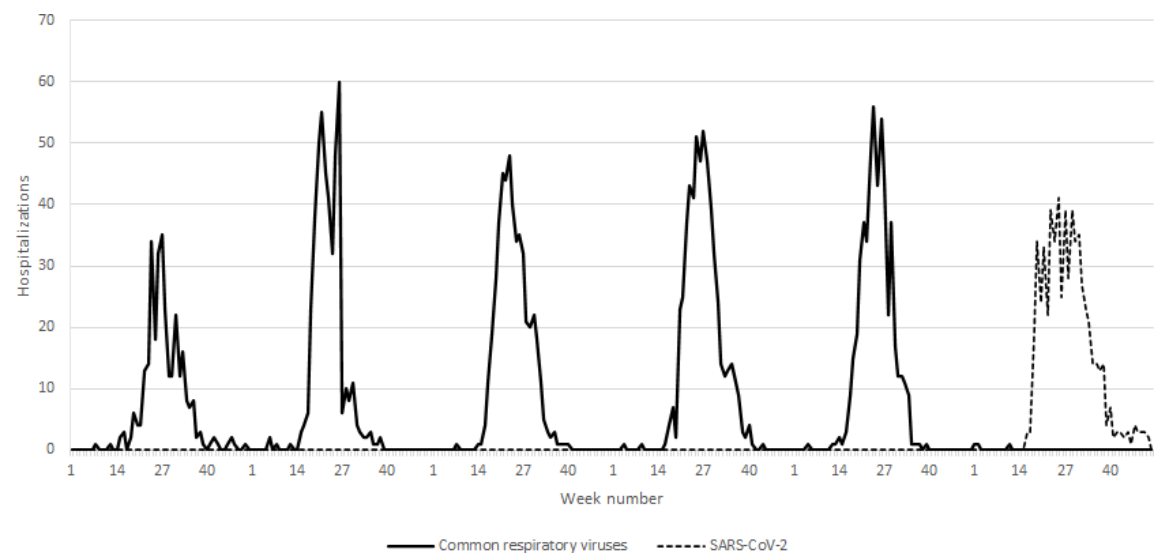

